\title{
Evidence of Calcitonin-Induced Inhibition of Calcitonin Secretion in Porcine Thyroid Slices
}

Anthony L. Orme, J. Thomas Pento

First Published January 1, 1976 Research Article

Article Information

Proceedings of the Society for Experimental Biology and Medicine, Volume: 151 issue: 1,page(s): 110-112

Issue published: January 1, 1976

\section{Abstract}

\section{Summary}

In the present study, the possibility of calcitonin-induced self-inhibition in porcine thyroid slices was examined. Replacing the incubation medium at 5-min intervals during incubation and increasing the volume of incubation from 2 to $15 \mathrm{ml}$ were observed to enhance calcium-stimulated calcitonin secretion in vitro.

The authors gratefully acknowledge the generous supply of porcine thyroids by $\mathrm{Mr}$. T. F. Andreskowski of Wilson and Co., and the technical assistance of Mrs. Patricia Reese. This study was supported in part by NSF Grant GB-43214. 